\section{NOVA TELLVS}

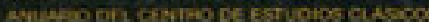

Nova Tellus

ISSN: 0185-3058

novatelu@servidor.unam.mx

Centro de Estudios Clásicos

México

Huerta Cabrera, Yazmín Victoria

El ideal educativo del orador en los prefacios de Séneca el Viejo

Nova Tellus, vol. 26, núm. 2, 2008, pp. 223-250

Centro de Estudios Clásicos

Distrito Federal, México

Disponible en: http://www.redalyc.org/articulo.oa?id=59115497010

- Cómo citar el artículo

- Número completo

- Más información del artículo

- Página de la revista en redalyc.org

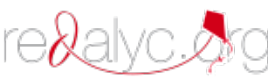

Sistema de Información Científica

Red de Revistas Científicas de América Latina, el Caribe, España y Portugal

Proyecto académico sin fines de lucro, desarrollado bajo la iniciativa de acceso abierto 


\title{
El ideal educativo del orador en los prefacios de Séneca el Viejo
}

\author{
Yazmín Victoria HuERTA CABRERA \\ Universidad Nacional Autónoma de México \\ iasmine11@gmail.com
}

RESUMEN: El objetivo de este escrito consiste en comparar las ideas de tres escritores, Cicerón, Quintiliano y Séneca el Viejo sobre la educación romana, con especial atención a la formación del orador perfecto. Se pretende encontrar en los prefacios de la obra de Séneca el Viejo coincidencias y divergencias con el pensamiento de los mencionados autores.

ABSTRACT: The purpose of this writing is to compare the ideas on Roman education by three authors: Cicero, Quintilian, Seneca the Elder, with a special focus on the shaping of a perfect orator. An attempt is made to discover points of coincidence with and divergence from the thought of the former two authors in the prefaces of the latter's works.

PALABRAS CLAVE: Cicerón, educación, modelo del orador, Quintiliano, retórica, Séneca el Viejo.

RECEPCIÓN: 4 de julio de 2008.

ACEPTACIÓN: 3 de noviembre de 2008. 


\title{
El ideal educativo del orador en los prefacios de Séneca el Viejo
}

\author{
Yazmín Victoria HueRTa CABRERA
}

La identidad y la obra de Séneca el Viejo fueron confundidas con las obras de su hijo, Séneca el Filósofo, durante la Edad Media. ${ }^{1}$ No obstante, esta confusión permitió que su producción literaria se salvara del olvido y se transmitiera hasta que, después de varios siglos, llamara la atención de numerosos estudiosos modernos.

Las breves referencias que el autor nos proporciona en su obra, señalan que las guerras civiles le impidieron salir de su provincia y escuchar a Cicerón declamando ante dos jóvenes, los conocidos cónsules Hircio y Pansa. ${ }^{2}$ Este suceso fechado en el año 43 a. C., permite suponer que por ese tiempo contaba con doce o dieciséis años, edad conveniente para iniciar el nivel del rhetor. ${ }^{3}$ De ahí que se conjeture que nació entre el 58 o el 55 a. C., y murió, probablemente, en el 39 d. C. ${ }^{4}$ Su juventud

\footnotetext{
${ }^{1}$ Véase la Introducción de Ignacio Adiego Lajara, et al., en Controversias Libros I-V, Séneca el Viejo, Madrid, Gredos, 2005.

${ }^{2}$ Contr. I, praef. 11: Omnes autem magni in eloquentia nominis excepto Cicerone videor audisse; ne Ciceronem quidem aetas mihi eripuerat, sed bellorum civilium furor, qui tunc orbem totum pervagabatur, intra coloniam meam me continuit: alioqui in illo atriolo, in quo duos grandes praetextatos ait secum declamasse, potui adesse, illudque ingenium, quod solum populus Romanus par imperio suo habuit, cognoscere et, quod vulgo aliquando dici solet, sed in illo proprie debet, potui vivam vocem audire.

${ }^{3}$ Sussman, The elder Seneca, Leiden, Brill, 1978, p. 20

${ }^{4}$ Las fechas de su nacimiento y de muerte son imprecisas. Hay quienes sitúan la primera entre el 60 y el 50 a. C., la segunda entre los años 37 y 41 d. C. Vid. Introducción de Ignacio Adiego Lajara, et al., en ibid., pp. 10, 19.
} 
transcurrió como la de cualquier hijo de familia acomodada, ya que perteneció a la clase ecuestre; luego, decidió dejar su Córdoba natal para dirigirse a Roma con el fin de perfeccionar sus estudios en compañía de un amigo. Su estancia se prolongó en la urbe, pero al fin regresó a su provincia y durante ese periodo se casó con Helvia y tuvo tres hijos. Pasado el tiempo se mudó con su familia a Roma en los primeros años del siglo I d. C. y allí frecuentó los círculos literarios de oradores y rétores. Pero su estancia no fue permanente en la urbe romana porque con recurrencia volvía a su provincia. En cuanto a su personalidad, Séneca, hijo, nos refiere que su padre era un hombre conservador (maiorum consuetudini deditus) y poseía un temperamento severo (patris mei antiquus rigor, Ad Helv., 17, 3). Entre sus principales virtudes, Séneca el Viejo destacó por su memoria; ${ }^{5}$ no podía esperarse menos de un hombre cuyas dotes estaban implícitas en sus tria nomina: Lucius $(<l u x)$, sobre todo hablando de su lucidez; Annaeus ( $<$ annus) y Seneca (< senex); al parecer estos últimos apelativos denotaban su longevidad. ${ }^{6}$

Su obra heredada a la posteridad es la titulada Oratorum et rhetorum sententiae, divisiones, colores, conocida comúnmente como Controversias y Suasorias, de ella se han conservado cinco libros de ejercicios judiciales y uno de ejercicios deli-

\footnotetext{
${ }^{5}$ Contr. I, praef. 2: Hanc aliquando adeo in me floruisse, ut non tantum ad usum sufficeret sed in miraculum usque procederet, non nego; nam et duo milia nominum recitata quo erant ordine dicta reddebam et ab his, qui ad audiendum praeceptorem mecum convenerant, singulos versus a singulis datos, cum plures quam ducentiefficerentur, ab ultimo incipiens usque ad primum recitabam.

${ }^{6}$ Es conveniente recordar que la designación del nombre personal integrado por tres elementos, praenomen, nomen y cognomen, a lo largo de la historia sufrió cambios. Muchos praenomina latinos, por ejemplo, Quintus o Sextus, tenían un origen numérico relacionado con el día o mes de nacimiento; en época temprana el gentilicio, nomen, tuvo su origen de los patronímicos señalados con el sufijo -ius; y los cognomina denotaban características físicas (Longus), cualidades mentales (Clemens), circunstancias (Felix), ocupaciones (Agricola) y apelativos (Cato). Cf. OCD, pp. 1024-1026.
} 
berativos, a esto se agregan siete prefacios dedicados a diferentes personalidades de la elocuencia de la época augusta. De esta última unidad me ocuparé en el presente trabajo, cuyo objetivo será exponer brevemente el ideal educativo que Cicerón y Quintiliano ${ }^{7}$ configuraron y compararlo con el de Séneca el Viejo, que, desde mi punto de vista, coincide con el de estos notables escritores.

\section{El ideal educativo de Cicerón}

Cicerón escribió, dentro de su numerosa producción literaria, una trilogía sobre la elocuencia y la retórica, De oratore, Brutus, Orator, encaminada a delinear al orador ejemplar. Estas obras fueron escritas en el periodo del año 55 al 46 a. C. ${ }^{8}$ De todas ellas se pueden obtener varios rasgos para formar una concepción cabal del orador.

Ahora bien, Cicerón reconoce que la imagen perfecta del orador que persigue hasta ese momento es un ideal; si existiera, en tal caso dicho orador anhelado, no admitiría superación. ${ }^{9}$ Este hombre idealizado debe reunir ciertas cualidades o dones naturales que Cicerón señala como primordiales para ser un excelente orador: gozar de buena voz y de fuerza física, ser de apariencia conveniente, tener facilidad y soltura de palabra. ${ }^{10}$ Todo esto, sin duda, es otorgado por la natura o bien por el ingenium. ${ }^{11}$ Juntamente con estos atributos no menos importantes, es necesario que ese varón tenga una suma autoridad,

\footnotetext{
${ }^{7}$ Por razones de método expositivo he optado por no seguir un criterio cronológico y anteponer a Quintiliano en lugar de Séneca.

${ }^{8}$ Cicerón, Bruto, intr., trad. y notas de Manuel Mañas Nuñez, Madrid, Alianza Editorial, 2000.

${ }^{9}$ Cic., Or., 7-10.

${ }^{10}$ Cic., De orat., I, 113-115.

${ }^{11}$ Ibid., I, 113: Naturam primum atque ingenium ad dicendum vim adferre maximam.
} 
una suma virtud y sea un gran hombre dotado de sabiduría. ${ }^{12}$ En la concepción de Cicerón, este cimiento moral es necesario para conducir a los hombres a través de la elocuencia a cosas útiles y benéficas. ${ }^{13}$

Otro elemento que interviene en la formación del orador es el ars o la doctrina. Cicerón comenta que es un medio que sirve a los hombres capaces para perfeccionar sus cualidades, y a los mediocres para superarlas. ${ }^{14}$ Ambas, natura y ars, son indispensables en la educación del orador. Pero esto no basta, es necesario también tener studium et ardor amoris para llegar al punto que se quiere alcanzar. ${ }^{15}$

La preparación es sumamente trascendental para llegar a ser un orador destacado; por ello, Cicerón sugiere una serie de ejercitaciones previas: improvisar casos ficticios, escribir disertaciones, aprender de memoria versos, parafrasear discursos de oradores griegos, ejercitar la voz, el cuerpo y el gesto imitando a los mejores actores, ${ }^{16}$ una vez practicados en casa estos ejercicios, conviene hacerlos en público. Recomienda, asimismo, hacer una lectura crítica de los poetas y escritores de todas las artes. ${ }^{17}$ Cicerón considera que el conocimiento de diversas disciplinas amplía la cultura del orador; por ello, no se cansa de aconsejar que el orador debe saber, en primer lugar, filosofía, ${ }^{18}$ dominar el derecho civil, ${ }^{19}$ la historia nacional

\footnotetext{
${ }^{12}$ Cic., De Inv., I, 2-5: La diferencia que se establece entre el hombre sabio y respetable que se sirve de la elocuencia y los hombres entregados a la mentira que hacen mal uso de ella.

${ }^{13}$ Cic., De Inv., I, 1: qui vero ita sese armat eloquentia, ut non oppugnare commoda patriae, sed pro his propugnare possit, is mihi vir et suis et publicis rationibus utilissimus atque amicissimus civis fore videtur.

${ }^{14}$ Cic., De orat., I, 115: Neque enim haec ita dico, ut ars aliquos limare non possit -neque enim ignoro, et quae bona sint, fieri meliora posse doctrina et, quae non optima, aliquo modo acui tamen et corrigi posse.

${ }^{15}$ Ibid., I, 134-135.

${ }^{16}$ Ibid., I, 149-157.

${ }^{17}$ Ibid., I, 158.

${ }^{18}$ Cic., Orat., 14-16; 118.

${ }^{19}$ Cic., Orat., 120.
} 
y extranjera, ${ }^{20}$ la dialéctica ${ }^{21}$ e, incluso, tener rudimentos de física. $^{22}$

Con todas estas herramientas, el orador se encuentra preparado para cumplir con sus principales finalidades frente al público: convencer, deleitar y conmover ${ }^{23}$ No obstante, para alcanzar estos objetivos, Cicerón observa una cualidad más: un estilo oratorio conveniente a cada situación, es decir, un modo de hablar que se adapte a los temas, a las circunstancias y a las personas, para ello el orador debía tener un gran criterio para discernir en cada caso qué era lo apropiado al discurso, a las palabras y, sobre todo, a la causa. ${ }^{24}$

Aunque parecería que este utópico individuo no existiría más que en la mente del arpinate, resulta que en un esbozo autobiográfico del Bruto aparece encarnado este ansiado prototipo en la imagen y figura del mismísimo Cicerón, quien sobresalió ante todo por sus cualidades innatas e instrucción técnica:

De mí nada diré: hablaré de los demás, de los cuales no había nadie que pareciera que se había aplicado a la literatura con mayor cuidado que el vulgo de los hombres, en la cual se contiene la fuente de la perfecta elocuencia; nadie que hubiera abrazado la filosofía, madre de todas las buenas acciones y de las bellas palabras; nadie que hubiera aprendido el derecho civil, materia necesaria sobre todo para las causas privadas y para el conocimiento del orador; nadie que guardara memoria de los asuntos romanos, de donde, si alguna vez hubiera necesidad, resucitara a los testigos más calificados de los infiernos; nadie que, una vez encerrado el adversario, calmara los ánimos de los jueces en poco tiempo y sutilmente y llevara un momento de la severidad a la hilaridad y la risa; nadie que pudiera alargar el discurso y conducirlo desde una discusión propia y determinada de un

\footnotetext{
${ }^{20}$ Idem.

${ }^{21}$ Ibid., 113.

22 Ibid., 119.

${ }^{23}$ Ibid., 69-72; De opt. gen. orat., I, 3.

${ }^{24}$ Cic., Orat., 69-74.
} 
hombre y de una circunstancia hasta una cuestión común de todo género; nadie que para deleitar se apartara por un momento de la causa; nadie que pudiera conducir con insistencia al juez a la ira; nadie que pudiera llevarlo al llanto; nadie que pudiera sacudir su ánimo, que es la única cosa sobre todo propia del orador, adondequiera que demandara la materia. ${ }^{25}$

Ahora bien, ya que este ideal había descendido de las esferas celestes para adquirir forma y figura, Cicerón refiere la utilidad de ese hombre en la tierra: sirviéndose de la elocuencia y poseyendo todo un bagaje genético, moral y disciplinario este vir debía proteger y defender los intereses comunes de la República:

De aquí en Atenas magnas discordias, en nuestra República no sólo sediciones, sino también desastrosas guerras civiles. Un ciudadano de gran autoridad y fuerte y digno del primer cargo en la República evitará y aborrecerá estos males y se entregará completamente a la República y no tratará de conseguir riqueza o poder y así la defenderá entera, de tal manera que cuide el bienestar de todos. Pero no expondrá a alguno con falsos crímenes al odio o a la envidia y de tal manera se aferrará por completo a la justicia y honestidad que, con tal de mantenerlas, por más que tenga tropiezos penosamente, incluso se entregue a la muerte antes que abandone aquellos preceptos que he dicho. ${ }^{26}$

En el año 46 a. C., después de la composición del Brutus, Cicerón escribió su obra De optimo genere oratorum, ${ }^{27}$ en la que propuso como modelo de orador perfecto a Demóstenes, ${ }^{28}$ y a

${ }^{25}$ Cic., Brut., 322. Esta traducción y las que se incluyen aquí son mías.

${ }^{26}$ Cic., De officis, I, 86.

${ }^{27}$ Esta ha sido la fecha acordada por algunos especialistas. Para la discusión de este dato, véase Cicerón, De optimo genere oratorum, intr., trad. y notas de José Quiñones Melgoza, México, Universidad Nacional Autónoma de México (Bitácora de Retórica, 13), 2000, p. 14.

${ }^{28}$ Cic., De opt. gen. orat., VI, 17; Orat., 23. 
su elocuencia ática como sinónimo del disertar bien. ${ }^{29}$ Demóstenes, llamado "el príncipe de los oradores", ${ }^{30}$ se distinguió, según Cicerón, por su elocución, por su estilo y expresión:

Pues, en verdad, del todo perfecto y a quien absolutamente nada faltaba sin dificultad designarías a Demóstenes. En esas causas que escribió no pudo encontrarse nada con ingenio, nada, por decirlo así, con artificio; nada con astucia, que él no concibiera; nada que se dijera con precisión; nada con violencia; nada con sencillez, en lo que pudiera hacerse algo más conciso; nada, por el contrario, ampuloso; nada impetuoso; nada adornado por la importancia o bien de las palabras, o bien de los pensamientos, en lo que hubiera algo más elevado. ${ }^{31}$

\section{El ideal educativo de Quintiliano}

La Institutio Oratoria, escrita en doce libros por Quintiliano, fue el fruto de su larga trayectoria como profesor de retórica latina y el legado educativo de la antigüedad clásica más valioso para la humanidad, ya que logró sistematizar los complejos principios de la doctrina retórica y los revistió de un tono didáctico. Su magna obra pretende formar al orador perfecto desde la cuna y acompañarlo hasta el momento de su retiro. El autor establece en el proemio del libro primero su meta educativa:

Ahora bien, formamos a aquel orador perfecto que no puede ser sino un hombre bueno, y por eso no sólo exigimos en él la facilidad extraordinaria de disertar, sino todas las virtudes del alma. Pues ni aprobaría que la enseñanza de una vida recta y honesta,

${ }^{29}$ Cic., De opt. gen. orat., IV, 13: Ex quo intellegitur, quoniam Graecorum oratorum praestantissimi sint ei qui fuerint Athenis, eorum autem princeps facile Demosthenes, hunc si qui imitetur, eum et Attice dicturum et optime, ut, quoniam Attici nobis propositi sunt ad imitandum, bene dicere id sit Attice dicere.

${ }^{30}$ Cic., Brut., 141.

${ }^{31}$ Cic., ibid., 35-36. 
como algunos pensaron, debe hacerse recaer sobre los filósofos, puesto que aquel hombre realmente político y capaz para la administración de los asuntos públicos y privados, que puede gobernar las ciudades con consejos, construirlas con leyes, corregirlas con sentencias, no es otro en verdad que el orador. ${ }^{32}$

Luego, más adelante, en libros posteriores añade:

Pues no formamos cierto instrumento forense ni una voz asalariada ni, para ahorrarnos palabras más severas, un defensor de pleitos no inútil realmente, a quien en fin llaman comúnmente causídico, sino un hombre que se distinga por la naturaleza de su ingenio, que abrace en su espíritu por completo tantas hermosísimas artes, entregado en fin a los asuntos humanos, al cual ninguna antigüedad antes haya conocido, único y perfecto en todos los sentidos, que piense las mejores cosas y que hable óptimamente. ${ }^{33}$

Por lo tanto, el orador ideal que Quintiliano pretende modelar debe ser un varón dotado de todas las virtudes, de pensamientos nobles y de un talento natural, instruido, además, en todas las bellas doctrinas. En otras referencias, Quintiliano enfatiza la formación moral, ${ }^{34}$ como fundamento principal para llegar a ser un excelente orador: "Porque no sólo digo esto, que es necesario que ése, el que sea orador, sea un hombre bueno, sino que ni siquiera será un orador si no es un hombre bueno". 35

De ahí que el vir bonus, poseedor de sólidas costumbres morales, sea el único y verdadero orador, según Quintiliano.

\footnotetext{
${ }^{32}$ Quint., Inst. Orat., I, Proem. 9-10.

${ }^{33}$ Ibid., XII, 1, 25.

${ }^{34}$ Cf. Antonio López Eire, Esencia y objeto de la Retórica, México, Universidad Nacional Autónoma de México, 1996, p. 47: "la retórica de verdad es para Quintiliano la retórica moral, la virtud hecha ciencia". Esta visión educativa coincide con la retórica isocrática, de la que nos advierte López Eire, pp. 44-46: la retórica fue concebida como paideía, más allá de un arte.

${ }^{35}$ Quint., ibid., XII, 1, 3. También en XII, 1, 9 precisa, al decir: Non igitur umquam malus idem homo et perfectus orator.
} 
No obstante, es inevitable que un hombre malo diga otra cosa que lo que piensa: nunca faltará el discurso honesto a los hombres buenos, nunca (pues también ellos mismos serán prudentes) la invención de las mejores cosas: la cual también, si ha sido privada de los adornos, sin embargo, por su naturaleza se embellece de modo suficiente, y alguna cosa no se dice elocuentemente, la cual se dice con honestidad. ${ }^{36}$

Todo este pensamiento del autor no hace más que recordar la sentencia pronunciada por Catón a su hijo Marco: vir bonus dicendi peritus; pero Quintiliano va más allá de este célebre apotegma, pues considera que "un hombre de bien" es el resultado de dos factores: de la educación familiar y de la escolar que haya tenido. El autor atribuye gran responsabilidad a los padres en los primeros años de vida del niño para inculcar buenas costumbres y un empleo apropiado del lenguaje, y a los maestros para formar hábitos de disciplina y estudio. Por lo tanto, el éxito de este ideal depende en gran medida de la educación recibida en el núcleo familiar, pues de aquí el orador sacará su arsenal moral.

Quintiliano coincide con Cicerón al afirmar que los dones otorgados por la naturaleza (la voz, la buena apariencia, la gracia, la fortaleza física) son sumamente importantes para consolidar la preparación técnica (ars):

No obstante, en primer lugar debe declararse que los preceptos y las artes nada valen si no ayuda la naturaleza. Por lo cual, al que le faltara ingenio, este tratado no será de mayor utilidad que sobre la agricultura para tierras estériles. También hay otras dotes innatas para cada uno, la voz, un pulmón resistente al trabajo, salud, constancia, elegancia, las cuales si resultaron módicas, pueden ser aumentadas con la ejercitación, pero a veces faltan de tal manera que echan a perder también las buenas dotes del ingenio y del estudio; así, estas mismas sin un maestro experto,

\footnotetext{
${ }^{36}$ Ibid., XII, 1, 30.
} 
sin estudio constante, sin ejercitación asidua e ininterrumpida de escribir, leer y hablar, por sí mismas no son útiles. ${ }^{37}$

Asimismo, Quintiliano estima que el orador debe poseer ciertas virtudes: carácter (praestantia animi), constancia (constantia), confianza en sí mismo (fiducia), fortaleza (fortitudo), armas poderosas frente a un auditorio. ${ }^{38}$

En consecuencia, la combinación de la educación familiar con los principios indispensables de la natura y la doctrina producirán, sin lugar a dudas, un orador íntegro. ${ }^{39}$

Quintiliano también estuvo de acuerdo con Cicerón en la formación que debía tener de manera obligada el orador. La cultura general era imprescindible; por ello, era necesario conocer disciplinas como la historia, ${ }^{40}$ el derecho civil ${ }^{41}$ la filosofía,${ }^{42}$ manejar adecuadamente las ramas que forman parte de esta doctrina: la lógica, ${ }^{43}$ la física, ${ }^{44}$ y la ética; ${ }^{45}$ igualmente recomendó tener nociones de música, ${ }^{46}$ y geometría. ${ }^{47}$ Todas estas artes constituían el complemento para la formación de un orador integral y universal.

Por otra parte, Quintiliano señaló el proceso educativo práctico que complementaba el teórico. La aparición pública para defender pleitos no debía dilatarse, pero tampoco anticiparse. ${ }^{48}$ La dificultad de las causas judiciales iba siendo mayor a me-

\footnotetext{
${ }^{37}$ Ibid., I, proem. 26-27.

${ }^{38}$ Ibid., XII, 5, 1-2.

${ }^{39}$ Ibid., II, 19, 1: Scio quaeri etiam naturane plus ad eloquentiam conferat an doctrina. Quod ad propositum quidem operis nostri nihil pertinet, neque enim consummatus orator nisi ex utroque fieri potest.

${ }^{40}$ Ibid., XII, 4, 2.

${ }^{41}$ Ibid., XII, 3, 1.

${ }^{42}$ Ibid., XII, 2, 1; 9; 20.

${ }^{43}$ Ibid., XII, 2, 10; 13.

${ }^{44}$ Ibid., XII, 2, 20.

${ }^{45}$ Ibid., XII, 2, 17.

${ }^{46}$ Ibid., I, 8.

${ }^{47}$ Ibid., I, 9.

${ }^{48}$ Ibid., XII, 6, 2-3.
} 
dida que el aprendiz tomaba confianza en el foro. ${ }^{49}$ El joven orador debía conocer completamente las razones del pleito y, una vez conocida a fondo la causa, asumir el carácter de juez para sentenciar las incoherencias del caso a fin de descubrir la verdad. ${ }^{50}$ Quintiliano, a través de sus preceptos, traza la imagen de este orador perfecto como defensor de causas justas, que evita privilegiar los intereses de los poderosos y ensalzar a los desvalidos contra éstos. ${ }^{51}$ Para este autor, el único pago que debe exigir el orador en su calidad de abogado es el agradecimiento. ${ }^{52}$ Luego de una larga experiencia en el foro, Quintiliano aconseja que la ocupación digna de un orador consumado debe ser la enseñanza o bien entregarse a escribir historia o un tratado de elocuencia. ${ }^{53}$

Quintiliano admiró a Cicerón a tal punto que lo consideró como el orador perfecto que representaba el prototipo ansiado; de ahí que el autor esté de acuerdo con la opinión general de que Cicerón no era ya el nombre de un hombre, sino el nombre de la elocuencia:

Sin duda, los oradores, incluso en particular, pueden igualar la elocuencia latina con la griega: pues a cualquiera de esos opondría con valentía a Cicerón. Y no ignoro cuán gran debate suscite contra mí, sobre todo porque no es el propósito que lo compare con Demóstenes en este momento: y no interesa por cierto, ya que pienso que Demóstenes debe leerse y más bien aprenderse de memoria en primer lugar. De éstos, yo juzgo que varias virtudes son semejantes: buen juicio, organización, método de estructurar, de preparar, de probar, en fin todo que es propio de la invención. En el hablar hay cierta diferencia: aquél es más conciso, éste más elocuente, aquél termina las frases con concisión, éste con más amplitud, aquél siempre lucha con agudeza, éste

\footnotetext{
${ }^{49}$ Ibid., XII, 6, 6-7.

${ }^{50}$ Ibid., XII, 8.

${ }^{51}$ Ibid., XII, 7, 6.

${ }^{52}$ Ibid., XII, 7, 12.

${ }^{53}$ Ibid., XII, 11, 4-6.
} 
a menudo también con autoridad, allí nada puede quitarse, aquí nada puede agregarse, en aquél hay más diligencia, en éste más carácter. Vencemos, ciertamente con gracia y patetismo, dos cosas que valen mucho en los afectos. Y quizá la ley de la ciudad le haya quitado los epílogos, pero hay cosas que los atenienses admiran, y aquella diferente forma del discurso latino nos permitiría menos. Ninguna rivalidad hay sin duda en las cartas, aunque de cada uno existen, o en los diálogos, los cuales él no tiene. Pero debe concederse en esto que fue el mejor, e hizo en gran parte a Cicerón, tan grande como es. Pues me parece que Marco Tulio, al haberse consagrado todo a la imitación de los griegos, imitó la fuerza de Demóstenes, la riqueza de Platón, el encanto de Isócrates. Pero no sólo consiguió con el estudio lo que fue óptimo en cada uno, sino que la felicísima abundancia de su inmortal ingenio sacó por sí misma muchísimas o más bien todas las virtudes. Pues, como dice Píndaro, no recoge las aguas de la lluvia, sino se desborda en un torbellino vivo, engendrado por cierto regalo de la providencia para que la elocuencia pusiera a prueba todas sus fuerzas. Pues ¿quién puede enseñar con más exactitud, conmover con más vehemencia? ¿Quién tuvo alguna vez un encanto tan grande? De manera que creerías que él consiguió aquello, que arranca, y puesto que aparta al juez de su opinión personal por su propia fuerza, no obstante, parece que aquél no es arrastrado, sino lo sigue. Ya en todo lo que dice hay una autoridad tan importante que avergonzaría no estar de acuerdo y no ejerce la diligencia de un abogado, sino la confianza de un testigo o juez, cuando a veces estas cosas, las cuales cada una apenas alguien podría conseguir con un esfuerzo bastante mayor, fluyen sin esfuerzo y aquel discurso en el que nada más hermoso se escuchó, no obstante, manifiesta evidentemente, una muy fecunda facilidad. Por lo cual no inmerecidamente se dijo por los hombres de su época que dominaba como rey en los juicios, pero entre la posteridad consiguió que Cicerón se considerara ya no el nombre de un hombre, sino el de la elocuencia. Así pues, miremos a éste, sea para nosotros éste el modelo propuesto; aquél sepa que él mismo ha progresado, a quien deleitara Cicerón en gran manera. ${ }^{54}$

\footnotetext{
${ }^{54}$ Ibid., X, 1, 105-112.
} 


\section{El ideal educativo de Séneca el Viejo}

En los prefacios de Séneca el Viejo también se hallan presentes las ideas que los anteriores autores habían expuesto para formar al orador ejemplar. Los elementos indispensables que deben encontrarse en un individuo que pretende dedicarse a la elocuencia, como ya lo había señalado Cicerón, y luego lo refrendaría Quintiliano, son el ingenium y el ars. ${ }^{55}$ En boca y con palabras de Casio Severo, ${ }^{56}$ Séneca expone indirectamente la importancia de la capacidad nata en el hombre para desempeñarse en cualquier ámbito. Casio Severo argumenta, de manera general, que no todo hombre puede sobresalir en todas las disciplinas, principalmente por una causa: el talento personal es limitado y sólo puede destacar en un área (Contr. III, praef. 8). Para demostrar este pensamiento, expone lo que podría llamarse "la teoría de la habilidad del ingenio", fundamentando su argumentación con exempla de diversa índole. Casio Severo refiere que Cicerón destacó en el género literario de la elocuencia; Virgilio se distinguió en la poesía; Salustio sobresalió en la historia y Platón en la filosofía. ${ }^{57}$

En el orden natural, Severo confirma que la fuerza física es comparable al ingenio. En cada uno de los hombres es desproporcionada y desigual:

Nadie es igual a otro luchando, uno sobresale para levantar una carga de gran peso; otro no suelta cualquier cosa que agarra, sino

\footnotetext{
${ }^{55}$ Casaceli, Francesco, "La formazione dell'oratore ideale nell'opera di Seneca Padre", Vichiana, 7, 1978, pp. 52-65, en especial véanse las pp. 54-57. El investigador italiano hace mención de la presencia de estos elementos en la obra de nuestro autor.

${ }^{56}$ Nació alrededor del 50 o 40 a. C. y murió probablemente en el 31 o 32 d. C. Escribió libelos difamatorios contra personas ilustres de la época de Augusto, quien lo persiguió judicialmente en virtud de la ley de lesa majestad. Fue exiliado a la isla de Creta en el año $12 \mathrm{~d}$. C. y luego en tiempo de Tiberio trasladado a la isla de Sérifo (Cícladas).

${ }^{57}$ Contr. III, praef. 8.
} 
que echa sus manos para detener a los carros que se desplazan en una pendiente..$^{58}$

Según Casio, en los animales la sagacidad para realizar ciertas tareas depende de la especie y del tipo de ejercitación:

Unos ejercitan a los perros para cazar el jabalí; otros, el ciervo; no de todos los caballos, aun cuando sean muy rápidos, es idónea la rapidez para los carros; unos soportan mejor al jinete; otros, el yugo. ${ }^{59}$

En el drama, los actores destacaron en un solo estilo por sus cualidades histriónicas, como es el caso de Púlades y de Batilo. ${ }^{60}$ En el mundo circense unos sobresalieron como púgiles, otros como gladiadores:

Aunque a Nomio no sólo se le reconoce la rapidez de los pies, sino que también se le reprocha, sus manos son bastante lentas; unos luchan con los hoplómacos; otros, óptimamente con los tracios; unos desean enfrentarse con un zurdo, así como otros lo temen. ${ }^{61}$

Finalmente, Casio expone ejemplos de la elocuencia, Pasieno y Pompeyo Silón, ambos oradores que no sobresalieron como declamadores:

Cuando nuestro amigo Pasieno empieza a hablar, inmediatamente después del exordio se produce la huida, todos regresamos para escuchar el epílogo. Sólo para quienes es inevitable escuchan las cosas intermedias. ${ }^{62}$

\footnotetext{
${ }^{58}$ Contr. III, praef. 9.

${ }^{59}$ Contr. III, praef. 9.

${ }^{60}$ Contr. III, praef. 10.

${ }^{61}$ Idem.

${ }^{62}$ Idem.
} 
Pompeyo Silón, permaneciendo sentado, es facundo y erudito y sería considerado elocuente, si despidiera al auditorio después del exordio; declama tan mal, que me parece haberle expresado muy bien cuando le dije: “iNunca te levantes!” La elocuencia es una disciplina excelsa y fecunda, y hasta ahora no ha favorecido a alguien, de tal modo que haya llegado a él toda entera; es bastante afortunado quien es admitido en alguna parte de ésta. ${ }^{63}$

Luego de estos casos, se concluye que la razón de esta desventaja es la misma que ha tratado de probar desde un principio: la naturaleza otorga a cada individuo un ingenium peculiar y determinado, que destaca en una disciplina por sus aptitudes propias.

En otro lugar, Séneca el Viejo se sirve del pensamiento de Vocieno Montano $^{64}$ para destacar el valor de la ejercitación. Para sustentar su opinión, Montano ofrece tres exempla sacados del ámbito lúdico, donde los gladiadores, los atletas y los corredores entrenaban con sumo rigor para el espectáculo que iban a presentar. ${ }^{65}$ Esta disciplina es necesaria para obtener resultados provechosos en cualquier ámbito. Este componente del ars o doctrina no es más que la tenacidad personal que contribuye a aumentar la instrucción teórica impartida por los entrenadores y da como resultado un pulimiento técnico. Ello también se aplica a la elocuencia.

Séneca padre, como precursor de Quintiliano, comparte la idea que resume la sentencia pronunciada por Catón el Censor: la calidad moral del orador es vital para hablar frente al público, ${ }^{66}$ por ello, se justifica su marcada preocupación por la decadencia de las costumbres morales de su época cuando la señala en el primer prefacio como la principal causa de re-

${ }^{63}$ Contr. III, praef. 11.

${ }^{64}$ No hay suficientes datos de este hombre, pero se sabe por Tácito, en los Anales, IV, 42, que Vocieno Montano fue acusado por haber pronunciado injurias contra Tiberio y procesado por el delito de lesa majestad.

${ }^{65}$ Contr. IX, praef. 4.

${ }^{66}$ Contr. I, praef. 9. 
troceso de la elocuencia. ${ }^{67}$ A partir de esto resulta que en Séneca también hay una estrecha relación entre ars y mos. ${ }^{68} \mathrm{De}$ ahí que, con lamentable expresión, manifieste su temor de ver depositada la elocuencia en hombres depravados. ${ }^{69}$

En cuanto a la personificación del paradigma oratorio, Séneca el Viejo no tiene preferencia por una sola persona que cumpla con estas pretensiones, en cambio manifiesta cierta admiración por cuatro hombres a los que llamó "la cuadriga oratoria”, integrada por Latrón, Fusco, Albucio y Galión. ${ }^{70}$ En efecto, en estos varones hubo cualidades dignas de elogiar y de emular. Sin embargo, no hay información completa y precisa de todos ellos en los prefacios conservados de nuestro autor, ya que al menos tres de estos últimos se han perdido. Es el caso de Galión, del que hay escasas referencias y del que podríamos obtener detalles más fiables a partir de sus intervenciones en las Controversias. Respecto a Fusco, en el prefacio segundo no hay suficientes testimonios de sus cualidades oratorias, excepto su splendida oratio (Contr. II, praef. 2), señalada por Séneca. No obstante, esto no niega ni demerita su papel dentro del cuarteto, incluso alienta más la búsqueda, en el resto de la obra, de precisiones sobre estas virtudes. De acuerdo con el prefacio séptimo, se puede decir de Albucio que fue un varón con más virtudes oratorias que vicios; sin embargo, permitía que los vicios afloraran en sus actuaciones públicas. De Latrón se ha afirmado, según Casaceli y Priobolu, que es el prototipo oratorio, ${ }^{71}$ la razón que sustenta esta

\footnotetext{
${ }^{67}$ Cf. Contr. I, praef. 6-10.

${ }^{68}$ Casaceli, op. cit., p. 57.

${ }^{69}$ Contr. I, praef. 9: Quis aequalium vestrorum quid dicam satis ingeniosus, satis studiosus, immo quis satis vir est? Emolliti enervesque, ut nati sunt, non inviti manent, expugnatores alienae pudicitiae, neglegentes suae. In hos ne dii tantum mali ut cadat eloquentia.

${ }^{70}$ Cf. Contr. X, praef. 13.

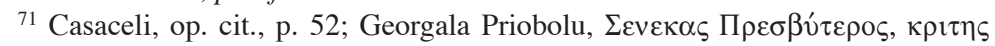

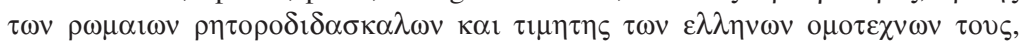
Parousia VI (341-351), 1988, pp. 344 y ss.
} 
afirmación se basa en primer lugar en que su personalidad es ampliamente descrita en el primer prefacio. La extensión de este elogio va desde el parágrafo 13 hasta el 24, es decir, representa casi un cincuenta por ciento del contenido.

La vívida y extensa semblanza que se hace de Latrón denota las aptitudes de este orador: una memoria privilegiada, un cuerpo firme, una voz fuerte, su amplio conocimiento de la historia, su característico estilo dotado de precisión, y su juicio estricto. Además, nos informa de su preferencia por las sentencias y su gusto por ejercitarse con entimemas y epifonemas. En contraste con todo lo anterior, su principal vicio es su apasionamiento (modus deerat) llevado in extremis. Al parecer, para Casaceli y Priobolu, la amplitud de la narración es un sinónimo de jerarquía, y no habría que dudarlo, dado que no en vano Séneca le concedió el primer puesto dentro de sus prefacios y el primer lugar dentro de la cuadriga, opinando que "todas las virtudes de la oratoria estaban en él". No obstante, difiero de esta postura y considero que aceptarla, sería contradecir los principios programados por el mismo Séneca en el primer prefacio: ofrecer el mayor número de modelos para avanzar más en la elocuencia. ${ }^{72}$ Ahora bien, sin negar las virtudes de Latrón, se considera que el motivo que tuvo Séneca para mencionarlo primeramente en los prefacios, fue que quiso rendir un homenaje a la memoria de su entrañable amigo, y la mejor forma de hacerlo, fue incluirlo dentro de su obra asignándole una posición destacada.

Así pues, Séneca selecciona a esos varones (Latrón, Fusco Albucio y Galión) por una necesidad de asignarles una posición jerárquica ${ }^{73}$ y de manifestar una preferencia personal en el ámbito de las corrientes retóricas del siglo I d. C. ${ }^{74}$ pero de ninguna manera parece ser que en su calidad de crítico

\footnotetext{
${ }^{72}$ Contr. I, praef. 6.

${ }^{73}$ Contr. X, praef. 13.

${ }^{74}$ Casaceli, op. cit., p. 64.
} 
literario opte por este selecto grupo como el paradigma oratorio. De todos los datos aportados en los prefacios se pueden obtener ciertas particularidades que delinean su modelo educativo.

En las biografías, Séneca muestra el aprecio por las cualidades innatas como la voz, una herramienta primordial para todo orador frente a su auditorio, ya que con ella lo persuadirá. La voz debe ser vigorosa (vox robusta, valentissima, solida) y melodiosa (suavitas, dulcis), atributos idóneos de este sonido, de ahí que oradores como Latrón, Fabiano y Severo ${ }^{75}$ gocen de reconocimiento por este don. Sin embargo, Séneca deja ver entre líneas que el no cuidarla y no educarla es la mayor negligencia que el orador puede cometer. Otra cualidad elogiada en Latrón es la memoria, un almacén con determinada capacidad con el que cuenta todo hombre, pero que puede ser incrementada gracias a la disciplina y a la ejercitación (plurimum tamen arte adiuta). Un temple singular (ingens, praesens, compositus, pacatus) es fundamental, ya que ese carácter (animus) determina el estilo oratorio del que habla y lo transmite al público con el fin de influir en él y conducirlo donde la situación lo requiera (nemo magis in sua potestate habuit audientium affectus; adfectus efficaciter movit). En Fabiano, Severo, Polión y Albucio Silón pueden advertirse estas consideraciones. En oposición a esto, Séneca reprueba en Haterio su débil carácter (animus imbecillus) manifestado en un discurso al recordar la muerte de su hijo. Un juicio cabal (iudicium strictum et asperum), como el de Polión, es útil para evaluar y valorar. Admirable en Latrón y en Severo es la apariencia física apropiada (corporis magnitudo conspicua, corpus solidum); un gesto y ademán convenientes (voltus habitusque corporis mire aptatus), como el de Escauro, constituyen la personalidad del orador para cautivar al público, y

\footnotetext{
${ }^{75}$ Véase más adelante el cuadro que reúne las "Virtudes y vicios oratorios de los oradores, rétores y declamadores", de las que se hablarán a partir de aquí.
} 
un talento privilegiado, (ingenium magnum, multum), sin el cual no se puede lograr nada. En cuanto a las mores, Séneca admira sobre todo en ciertos varones la gravitas y la diligentia, es decir, la seriedad en los asuntos y el esmero en ellos; lo opuesto a ellas, la desidia, es sutilmente reprobada.

En cuanto a la instrucción pedagógica, Cicerón y Quintiliano consideraban que una educación enciclopédica era básicamente el complemento de su formación oratoria; por el contrario, Séneca pensaba que la elocuencia es la plataforma elemental y necesaria para cualquier disciplina. ${ }^{76}$ Como ejemplo cabe mencionar el caso de Fabiano en el prefacio segundo, quien sobresalió por su facilidad para disertar en la filosofía. Posiblemente este hecho fue un fruto obtenido a partir de su educación declamatoria en la elocuencia. Asimismo nuestro autor estima que el orador no sólo debe estar instruido con conocimientos teóricos y técnicos proporcionados por el ars o doctrina, sino también debe complementar su enseñanza con la práctica. Casio Severo, Polión, Haterio, Escauro y Labieno se endurecieron con las contiendas verbales llevadas en el foro. En el caso de los declamadores, Séneca censura esta tendencia de limitarse sólo a la práctica escolar y olvidarse de ejercitarse en ese sitio. De esta manera, nuestro autor reprueba a aquellos declamadores, especialmente a Baso, que pretenden imitar la elocuencia del foro sin haberla conocido; y a aquellos, sobre todo a Albucio, que utilizan los mismos recursos retóricos de la escuela en los tribunales judiciales.

El varón ejemplar sugerido por Séneca es el que se distingue por su habilidad psicagógica frente al público, por su dicción selecta (phrasis electa), no vulgar (res dicebat omnium sordidissimas), por su estilo de hablar apasionado y enérgico (genus dicendi ardens et concitatum), por la riqueza de su vocabulario (numquam inopia verbi), por su pericia para hablar improvisadamente (dicere ex tempore), por la proporción

\footnotetext{
${ }^{76}$ Sen., Contr. II, praef. 3.
} 
de su discurso (summa inaequalitas orationis), por el ritmo pausado de éste (tanta erat illi velocitas orationis), por la fluidez natural de sus ideas y de sus palabras (cum verba velut iniussa fluebant), por la naturalidad de sus movimientos corporales y vocales (vocis nulla contentio, nulla corporis adseveratio), por su argumentación sólida y no compleja (argumentabatur moleste), por su exposición dotada de más ideas que de palabras (verborum illi tantum copia sed etiam rerum erat) y por sus expresiones impregnadas de fuerza y de brillo (sententiae vivae). Virtudes que encuentra reunidas en oradores como Latrón, Fabiano, Severo, Polión, Haterio, Albucio, Escauro y Esparso. Todo aquello que se aparte de estos lineamientos, ya sea por exageración o bien por precariedad, Séneca lo censura con habilidad. Éste es, por lo tanto, el ideal educativo al que se debe aspirar.

En síntesis: en estas tres concepciones en torno a un tema común se puede afirmar que Séneca otorgó cierta prioridad al elemento del ingenium y, de alguna manera, coincidió con la ideología de Cicerón y Quintiliano. Cada uno de estos escritores concedió suma importancia a este factor, es decir, el individuo destinado a ser orador debía poseer cierta cualidad innata (facultas dicendi) impregnada en la sangre. Ese varón nacía para la profesión que debía desempeñar a lo largo de su vida, y se hacía, o bien se forjaba con la técnica y la disciplina (ars): todo esto funciona como una predestinación para la elocuencia. Y la expresión más explícita la hace Séneca cuando afirma "Yo no la admiraría, si no seleccionara (sc. elocuencia) las almas a las que se entrega". ${ }^{77}$ De ahí que Casio Severo se justifique con el argumento del talento para exponer que él había nacido, por así decirlo, para ser orador y no declamador.

Obtenido este don y agregados los atributos naturales, sólo restaba, con el paso del tiempo, desarrollar y pulir ese talento

\footnotetext{
${ }^{77}$ Sen., Contr. I, praef. 9.
} 
con constancia ardua. Claro que ese individuo, como también lo señalan los autores, debía gozar de una calidad moral excelsa, ya que el estar frente a un auditorio implicaba el magno compromiso no sólo de pronunciar un discurso, sino de convencer a los oyentes a partir de proposiciones en las que uno mismo cree, piensa y dice. En otras palabras, el orador no puede convencer a su auditorio, si él mismo no está convencido de lo que afirma. En este aspecto, Quintiliano, a diferencia de Cicerón, puntualiza que el núcleo familiar es precisamente el semillero donde pueden germinar las virtudes que caracterizarán al orador, esto es, la virtud, según la visión del calagurritano, puede enseñarse. ${ }^{78}$ Para Séneca, la sociedad carente de buenas y sólidas costumbres no es más que engendradora de pésimos oradores, que serán nefastos modelos para generaciones futuras. En cuanto a la instrucción, Quintiliano es totalmente ciceroniano, uno y otro buscan un hombre culto y competente; en Séneca no hay apreciaciones manifiestas de las disciplinas en las que el orador debía instruirse; en contraste, expresa que la elocuencia es el punto de partida para otras áreas de estudio. Una coincidencia más que es conveniente notar en nuestros autores, sobre todo entre Cicerón y Quintiliano, es el modelo del político-orador, ${ }^{79}$ es decir, un líder docto con un código ético intachable, dispuesto a servir al Estado y a sus conciudadanos. De acuerdo con Séneca, al parecer, no hay una intención de esta clase, dado que las condiciones políticas en las que se desenvolvió no lo permitían: Augusto había instaurado y consolidado el Imperio y Tiberio lo había continuado, por lo tanto, un orador de esta categoría no tenía lugar en la Roma de nuestro autor.

En resumen, se concluye, entonces, que la relevancia que tiene Séneca el Viejo en comparación con Cicerón y Quintilia-

\footnotetext{
${ }^{78}$ Aubrey Gwynn, Roman Education. From Cicero to Quintilian, New York, Russell et Russell, 1964, p. 238.

${ }^{79}$ Francisco Pina Polo, Marco Tulio Cicerón, Barcelona, Ariel, 2005, pp. 329 ss.
} 
no es que, aunque no buscó formular una teoría sino más bien juzgar las circunstancias que lo rodeaban, se preocupó por la educación de los hombres de sus días, y al igual que los otros consideró que la plataforma necesaria para ser un buen orador era la instrucción retórica. 
VIRTUDES Y VICIOS ORATORIOS DE LOS ORADORES, RÉTORES Y DECLAMADORES

\begin{tabular}{|c|c|c|}
\hline Nombres & VIRTUDES & Vicios \\
\hline $\begin{array}{l}\text { Marco Porcio Latrón } \\
\text { (Declamador) }\end{array}$ & $\begin{array}{l}\text { Corpus illi erat et natura solidum et } \\
\text { multaexercitationeduratum (Contr. } \\
\text { I, praef. 16) } \\
\text { Vox robusta, sed surda (Contr. I, } \\
\text { praef. 16) } \\
\text { Memoria ei natura quidem felix, plu- } \\
\text { rimum tamen arte adiuta (Contr. } \\
\text { I, praef. 17) } \\
\text { In illo non tantum naturalis memo- } \\
\text { riae felicitas erat, sed ars summa } \\
\text { et ad comprehendenda quae tene- } \\
\text { re debebat et ad custodienda, adeo } \\
\text { ut omnes declamationes suas, } \\
\text { quascumque dixerat, tenere etiam } \\
\text { (Contr. I, praef. 18) } \\
\text { Historiarum omnium summa notitia } \\
\text { (Contr. I, praef. } 18 \text { ) } \\
\text { Cum in illo, si qua alia virtus fuit, } \\
\text { et subtilitas fuerit (Contr. I, praef. } \\
20 \text { ) } \\
\text { Iudicium autem fuit strictius (Contr. } \\
\text { I, praef. 23) }\end{array}$ & $\begin{array}{l}\text { Vehementi viro modus deerat } \\
\text { (Contr. I, praef.13) } \\
\text { Inmoderati adversus se imperii } \\
\text { fuit (Contr. I, praef. } 15) \\
\text { Studium eius prohiberi debebat, } \\
\text { quia regi non poterat (Contr. } \\
\text { I, praef. } 15) \\
\text { Nulla umquam illi cura vocis } \\
\text { exercendae (Contr. I, praef. } 16)\end{array}$ \\
\hline $\begin{array}{l}\text { Arelio Fusco } \\
\text { (Declamador) }\end{array}$ & $\begin{array}{l}\text { Erat explicatio splendida (Contr. II, } \\
\text { praef. } 1 \text { ) } \\
\text { Splendida oratio et magis lasciva } \\
\text { quam laeta }(\text { Contr. } \mathrm{II}, \text { praef. } 1)\end{array}$ & $\begin{array}{l}\text { Sed operosa et implicata (Contr. } \\
\text { II, praef. } 1 \text { ) } \\
\text { Cultus nimis adquisitus (Contr. } \\
\text { II, praef. 1) } \\
\text { Conpositio verborum mollior } \\
\text { (Contr. II, praef. 1) } \\
\text { Summa inaequalitas orationis, } \\
\text { quae modo exilis erat, modo } \\
\text { nimia licencia vaga et effusa } \\
\text { (Contr. II, praef. 1) } \\
\text { Principia, argumenta, narratio- } \\
\text { nes aride dicebantur (Contr. } \\
\text { II, praef. } 1 \text { ) } \\
\text { Luxuria (Contr. II, praef. 2) }\end{array}$ \\
\hline $\begin{array}{l}\text { Papirio Fabiano } \\
\text { (Filósofo) }\end{array}$ & $\begin{array}{l}\text { Dicebat dulces sententiae (Contr. II, } \\
\text { praef. } 2 \text { ) } \\
\text { Splendor velut voluntarius non ela- } \\
\text { boratae orationi aderat (Contr. II, } \\
\text { praef. } 2 \text { ) } \\
\text { Vultus dicentis lenis et pro tranquil- } \\
\text { litate morum remissus (Contr. II, } \\
\text { praef. } 2 \text { ) } \\
\text { Vocis nulla contentio, nulla corporis } \\
\text { adseveratio (Contr. II, praef. } 2 \text { ) } \\
\text { Cum verba velut iniussa fluebant } \\
\text { (Contr. II, praef. } 2 \text { ) } \\
\text { Conpositus et pacatus animus (Contr. } \\
\text { II, praef. } 2 \text { ) }\end{array}$ & $\begin{array}{l}\text { Obscuritas (Contr. II, praef. 2) } \\
\text { Quaedam tam subito desinunt, } \\
\text { ut non brevia sint, sed abrup- } \\
\text { ta (Contr. II, praef. } 2 \text { ) } \\
\text { Deerat illi oratorium robur et } \\
\text { ille pugnatorius mucro (Contr. } \\
\text { II, praef. } 2 \text { ) }\end{array}$ \\
\hline
\end{tabular}




\begin{tabular}{|c|c|c|}
\hline Nombres & VIRTUDES & Vicios \\
\hline $\begin{array}{l}\text { Papirio Fabiano } \\
\text { (Filósofo) }\end{array}$ & $\begin{array}{l}\text { Suasoriis aptior erat (Contr. II, } \\
\text { praef. } 3 \text { ) } \\
\text { Numquam inopia verbi substitit, sed } \\
\text { velocissimo ac facillimo cursu om- } \\
\text { nes res beata circumfluebat oratio } \\
\text { (Contr. II, praef. } 3 \text { ) }\end{array}$ & \\
\hline $\begin{array}{l}\text { Casio Severo } \\
\text { (Orador) }\end{array}$ & $\begin{array}{l}\text { Oratio eius erat valens, culta, vigen- } \\
\text { tibus plena sententiis (Contr. III, } \\
\text { praef. } 2 \text { ) } \\
\text { Omnia intenta, aliquid petentia } \\
\text { (Contr. III, praef. } 2 \text { ) } \\
\text { Nemo magis in sua potestate habuit } \\
\text { audientium affectus (Contr. III. } \\
\text { praef. } 2 \text { ) } \\
\text { Auditus longe maior erat quam lec- } \\
\text { tus (Contr. III, praef. } 3 \text { ) } \\
\text { Corporis magnitudo conspicua } \\
\text { (Contr. III, praef. } 3 \text { ) } \\
\text { Suavitas valentissimae vocis (Contr. } \\
\text { III, praef. } 3 \text { ) } \\
\text { Pronuntiatio quae histrionem posset } \\
\text { producere (Contr. III, praef. } 3 \text { ) } \\
\text { Gravitas, quae deerat vitae, actioni } \\
\text { supererat (Contr. III, praef. } 4 \text { ) } \\
\text { Censoria oratio erat (Contr. III, } \\
\text { praef. } 4 \text { ) } \\
\text { Vir enim praesentis animi et maioris } \\
\text { ingenii (Contr. III, praef. } 4 \text { ) } \\
\text { Iratus commodius dicebat (Contr. } \\
\text { III, praef. } 4 \text { ) } \\
\text { Ex tempore coactus dicere infinito se } \\
\text { antecedebat (Contr. III, praef. } 6 \text { ) } \\
\text { Phrasis electa (Contr. III, praef. } 7 \text { ) } \\
\text { Genus dicendi ardens et concitatum } \\
\text { (Contr. III, praef. } 7 \text { ) } \\
\text { Explicationes habentes plus sen- } \\
\text { suum quam verborum (Contr. III, } \\
\text { praef. } 7 \text { ) } \\
\text { Diligentia (Contr. III, praef. } 7 \text { ) } \\
\text { Sententiae vivae (Contr. III, praef. } \\
\text { 18) }\end{array}$ & $\begin{array}{l}\text { Declamationes eius inaequales } \\
\text { erant (Contr. III, praef. 18) } \\
\text { Compositio aspera et quae vi- } \\
\text { taret conclusiones (Contr. III, } \\
\text { praef. } 18 \text { ) }\end{array}$ \\
\hline $\begin{array}{l}\text { Asinio Polión } \\
\text { (Orador) }\end{array}$ & $\begin{array}{l}\text { Floridior erat aliquanto in decla- } \\
\quad \text { mando (Contr. IV, praef. } 3 \text { ) } \\
\text { Homo natura contumax (Contr. IV, } \\
\text { praef. } 4 \text { ) } \\
\text { Ingens animus (Contr. IV, praef. } 6)\end{array}$ & $\begin{array}{l}\text { Illud strictum eius et asperum et } \\
\text { nimis iratum ingenio suo iudi- } \\
\text { cium adeo cessabat, ut in mul- } \\
\text { tis illi venia opus esset (Contr. } \\
\text { IV, praef. } 3 \text { ) }\end{array}$ \\
\hline $\begin{array}{l}\text { Quinto Haterio } \\
\text { (Orador) }\end{array}$ & $\begin{array}{l}\text { Declamabat ex tempore (Contr. IV, } \\
\text { praef. } 7 \text { ) } \\
\text { In latinam linguam transtulit grae- } \\
\text { cam facultatem (Contr. IV, praef. } \\
7 \text { ) } \\
\text { Verborum illi tantum copia sed etiam } \\
\text { rerum erat (Contr. IV, praef. } 7 \text { ) }\end{array}$ & $\begin{array}{l}\text { Animus imbecillus (Contr. IV, } \\
\text { praef. 6) } \\
\text { Tanta erat illi velocitas oratio- } \\
\text { nis, ut vitium fieret (Contr. IV, } \\
\text { praef. } 7 \text { ) } \\
\text { Quotiens velles eandem rem et } \\
\text { quamdiu velles diceret, aliis } \\
\text { totiens figuris, aliis tractatio- } \\
\text { nibus, ita ut regi posset nec } \\
\text { consumi (Contr. IV, praef. } 7 \text { ) }\end{array}$ \\
\hline
\end{tabular}




\begin{tabular}{|c|c|c|}
\hline NOMBRES & VIRTUDES & Vicios \\
\hline $\begin{array}{l}\text { Quinto Haterio } \\
\text { (Orador) }\end{array}$ & & $\begin{array}{l}\text { Regi ab ipso non poterat (Contr. } \\
\text { IV, praef. 8) } \\
\text { Non verba custodiebat (Contr. } \\
\text { IV, praef. 9) } \\
\text { Saepe incidebat in ea, quae de- } \\
\text { risum effugere non possent } \\
\text { (Contr. IV, praef. } 10 \text { ) }\end{array}$ \\
\hline $\begin{array}{l}\text { Albucio Silón } \\
\text { (Declamador) }\end{array}$ & $\begin{array}{l}\text { Splendor orationis (Contr. VII, } \\
\text { praef. 2) } \\
\text { Phrasis (Contr. VII, praef. 2) } \\
\text { Facultas extemporalis (Contr. VII, } \\
\text { praef. 2) } \\
\text { Sententiae simplices, apertae, vo- } \\
\text { cales et splendidae (Contr. VII, } \\
\text { praef. 2) } \\
\text { Adfectus efficaciter movit (Contr. VII, } \\
\text { praef. 3) } \\
\text { Figurabat egregie (Contr. VII, praef. } \\
\text { 3) } \\
\text { Locum beate implebat (Contr. VII, } \\
\text { praef. 3) } \\
\text { Copia sermonis latini (Contr. VII, } \\
\text { praef. 3) } \\
\text { Vis explicandi (Contr. VII, praef. } 3 \text { ) } \\
\text { Splendidissimus erat (Contr. VII, } \\
\text { praef. 3) }\end{array}$ & $\begin{array}{l}\text { Illa intempestiva in declamatio- } \\
\text { nibus eius philosophia sine } \\
\text { modo tunc et sine fine evaga- } \\
\text { batur (Contr. VII, praef. 1) } \\
\text { Raro totam controversiam imple- } \\
\text { bat (Contr. VII, praef. 1) } \\
\text { Cum populo dicebat, omnes vires } \\
\text { suas advocabat et ideo non de- } \\
\text { sinebat (Contr. VII, praef. 1) } \\
\text { Argumentabatur moleste (Contr. } \\
\text { VII, praef. 1) } \\
\text { Non implebat quaestionem (Contr. } \\
\text { VII, praef. 2) } \\
\text { Praeparabat suspiciose (Contr. } \\
\text { VII, praef. 3) } \\
\text { Inaequalitatem in illo mirari li- } \\
\text { cebat (Contr. VII, praef. } 3 \text { ) } \\
\text { Idem res dicebat omnium sordi- } \\
\text { dissimas (Contr. VII, praef. } 3 \text { ) } \\
\text { Nulla erat fiducia ingenii sui } \\
\text { (Contr. VII, praef. 5) } \\
\text { Idiotismus (Contr. VII, praef. 5) }\end{array}$ \\
\hline $\begin{array}{l}\text { Escauro } \\
\text { (Orador) }\end{array}$ & $\begin{array}{l}\text { Nihil erat illo venustius, nihil para- } \\
\text { tius (Contr. X, praef. } 2 \text { ) } \\
\text { Genus dicendi antiquum (Contr. X, } \\
\text { praef. } 2 \text { ) } \\
\text { Verborum non vulgarium gravitas } \\
\quad \text { (Contr. X, praef. } 2 \text { ) } \\
\text { Voltus habitusque corporis mire ad } \\
\text { auctoritatem oratoriam aptatus } \\
\text { (Contr. X, praef. } 2 \text { ) } \\
\text { Magni neglectique ingeni vestigium } \\
\text { extabat (Contr. X, praef. } 3 \text { ) }\end{array}$ & $\begin{array}{l}\text { Dicebat neglegenter (Contr. X, } \\
\text { praef. } 2 \text { ) } \\
\text { Desidia longa, immo perpetua } \\
\text { (Contr. X, praef. } 3 \text { ) } \\
\text { Illum longa, immo perpetua de- } \\
\text { sidia perduxerat (Contr. X, } \\
\text { praef. } 3 \text { ) }\end{array}$ \\
\hline $\begin{array}{l}\text { Tito Labieno } \\
\text { (Orador) }\end{array}$ & $\begin{array}{l}\text { Color orationis antiquae, vigor no- } \\
\text { vae (Contr. X, praef. } 5 \text { ) } \\
\text { Cultus inter nostrum ac prius saecu- } \\
\quad \text { lum medius (Contr. X, praef. } 5 \text { ) } \\
\text { Animus inter vitia ingens et ad si- } \\
\quad \text { militudinem ingenii sui violentus } \\
\text { (Contr. X, praef. } 5)\end{array}$ & \\
\hline $\begin{array}{l}\text { Musa } \\
\text { (Rétor) }\end{array}$ & $\begin{array}{l}\text { Multum habuit ingeni (Contr. X, } \\
\text { praef. 9) }\end{array}$ & $\begin{array}{l}\text { Nihil habuit cordis (Contr. X, } \\
\text { praef. } 9 \text { ) } \\
\text { Omnia usque ad ultimum tumo- } \\
\text { rem perducta (Contr. X, praef. } \\
\text { 9) }\end{array}$ \\
\hline $\begin{array}{l}\text { Mosco } \\
\text { (Declamador) }\end{array}$ & $\begin{array}{l}\text { Non incommode dixit (Contr. X, } \\
\text { praef. } 10 \text { ) }\end{array}$ & $\begin{array}{l}\text { Oratio eius non figurata erat sed } \\
\text { prava (Contr. X, praef. } 10)\end{array}$ \\
\hline
\end{tabular}


HUERTA CABRERA / EL IDEAL EDUCATIVO DEL ORADOR EN SÉNECA EL VIEJO

\begin{tabular}{|c|c|c|}
\hline NOMBRES & VIRTUDES & Vicios \\
\hline $\begin{array}{l}\text { Pacato } \\
\text { (Rétor) }\end{array}$ & $\begin{array}{l}\text { Dicit non inurbane (Contr. X, praef. } \\
\text { 10) }\end{array}$ & $\begin{array}{l}\text { Natus ad contumelias omnium } \\
\text { ingeniis inurendas (Contr. X, } \\
\text { praef. } 10)\end{array}$ \\
\hline $\begin{array}{l}\text { Esparso } \\
\text { (Declamador) }\end{array}$ & $\begin{array}{l}\text { Dicebat violenter (Contr. X, praef. } \\
\text { 11) }\end{array}$ & Sed dure (Contr. X, praef. 11) \\
\hline $\begin{array}{l}\text { Baso } \\
\text { (Declamador) }\end{array}$ & & $\begin{array}{l}\text { Cui demptam velles quam con- } \\
\text { sectabatur amaritudinem et si- } \\
\text { mulationem actionis oratoriae } \\
\text { (Contr. X, praef. } 12)\end{array}$ \\
\hline $\begin{array}{l}\text { Gavio Silón } \\
\text { (Orador) }\end{array}$ & $\begin{array}{l}\text { Bene declamavit (Contr. X, praef. } \\
\text { 14) }\end{array}$ & \\
\hline $\begin{array}{l}\text { Clodio Turrino el padre } \\
\text { (Declamador) }\end{array}$ & $\begin{array}{l}\text { Solebat declamare studiose (Contr. } \\
\text { X, praef. } 14 \text { ) } \\
\text { Tantum superfuit illi virium (Contr. } \\
\text { X, praef. } 15 \text { ) } \\
\text { Sententias dicebat excitatas, insi- } \\
\text { diosas, aliquid petentis (Contr. X, } \\
\text { praef. } 15 \text { ) } \\
\text { Causas nemo diligentius proposuit, } \\
\text { nemo respondit paratius (Contr. X, } \\
\text { praef. } 16 \text { ) } \\
\text { Diligentia (Contr. X, praef. } 16)\end{array}$ & $\begin{array}{l}\text { Multum viribus dempserat dum } \\
\text { Apollodorum sequitur (Contr. } \\
\text { X, praef. 15) } \\
\text { Etiamsi ars abesset (Contr. X, } \\
\text { praef. 15) }\end{array}$ \\
\hline
\end{tabular}

